\title{
Management of releasable full denture in patient with pseudo jaw relation class III: a case report
}

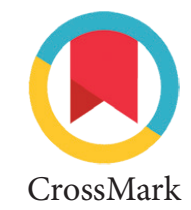

\author{
Elvi, Edy Machmud, ${ }^{*}$ Bahruddin Thalib, Armawati Arafi, Indah Sulistiawaty
}

Department of Prosthodontics, Faculty of Dentistry, Hasanuddin University, Makassar, Indonesia
*Correspondence to: Edy Machmud, Department of Prosthodontics, Faculty of Dentistry, Hasanuddin University, Makassar, Indonesia machmudedy@gmail.com

Received 05 0ctober 2016

Revised 22 November 2016 Accepted 03 January 2017 Available online 01 April 2017

\section{Abstract}

Objective: To give information about management of releasable full denture in patient with pseudo jaw relation class III

Methods: A 58 years old woman came with complaints that she could not chew food and felt shy when she laughed, the woman asked a denture made for her. Last tooth withdrawal was 3 months ago. Shape of upper jaw sharp edge is triangle (pointed alveolar ridge), while lower jaw sharp edge is in resorbtion condition. Making of denture was started with initial molding, physiology molding, bite determination and teeth arrangement based on Lingualized occlusion to insertion. Results: A case with pseudo jaw relation class III successfully treated using denture with lingualized occlusion.

Conclusion: Teeth arrangement using occlusion pattern Lingualized occlusion can give natural appearance to patient and stability of denture.

Keyword: Full denture, Pseudo jaw relation class III, Lingualized occlusion.

Cite this Article: Machmud EE, Thalib B, Arafi A, Sulistiawaty I. 2017. Management of releasable full denture in patient with pseudo jaw relation class III: A case report. Journal of Dentomaxillofacial Science 2(1): 58-60. D0l:10.15562/jdmfs.v2i1.453

\section{Introduction}

For edentulous patient who had lost all or half of teeth is suggested to apply denture. Posterior teeth loss can affect the stability vanishing of neuromuscular mandibular, decrease chewing efficiency and aesthetics. Therefore, wearing denture can restore the function of teeth even mastication function, phonetics and aesthetics function. To gain those functions, all steps of denture have to be watched carefully. If one of the steps is not performed appropriately, comfort and function of denture will decrease. ${ }^{1}$

In case of teeth loss that is not replaced with denture, alveolar bone resorption can occur from time to time. Speed level of alveolar sharp edge resorption is different between upper and lower jaw and resorption speed of lower jaw is greater than upper jaw. Resorption of alveolar sharp edge in part of upper jaw anterior is disposed to anterior direction and interior direction with level of progressive bone vanishing. Resorption of upper jaw posterior is disposed to anterior and interior direction so that alveolar sharp edge wanes progressively. Jaw relation that seems is pseudo jaw relation class III. ${ }^{2}$

To gain stability, aesthetics and good function of that jaw condition one treatment that can be performed is by making posterior teeth arrangement, lingualized occlusion. Lingualized occlusion is occlusion pattern with cusp palatal posterior of upper jaw teeth contact to fosa centralis posterior of lower jaw. So that all of the forces that emerge during working and balancing movements decrease and create stability naturally. ${ }^{3,4}$
Then in this case report, to get appearance alike original teeth and upper jaw stability which is in resorption condition greater than lower jaw the arrangement of posterior teeth with lingualized occlusion was performed.

\section{Case Report}

A 58 years old woman came to Prosthodontics Clinic, Dental Hospital Hasanuddin University, Makassar, Indonesia and she wanted a denture made because she felt shy as she laughedand she could not chew properly. Last tooth with-drawal for tooth 26 was done 3 months ago.

Figure 1 based on examination result, it seemed that shape of upper jaw sharp edge was triangle (pointed alveolar lingir) while lower jaw sharp edge was in resorption condition. From radiography examination, there was bone loss that spread evenly in lower jaw which caused sharp edge flat.

Initial treatment was performed by anatomical molding in patient using irreversible hydrocolloid. Based on anamnesis result and patient model study, patient was advised to make full denture in upper jaw and lower jaw from acrylic. After making of individual molding spoon from acrylic autopolymerisation, patient was performed border molding and physiological molding in the next visitation by retromylohioid molding technique in lower jaw with elastomer molding material figure 2.

Figure 3 in the next visitation, parallel determi- 


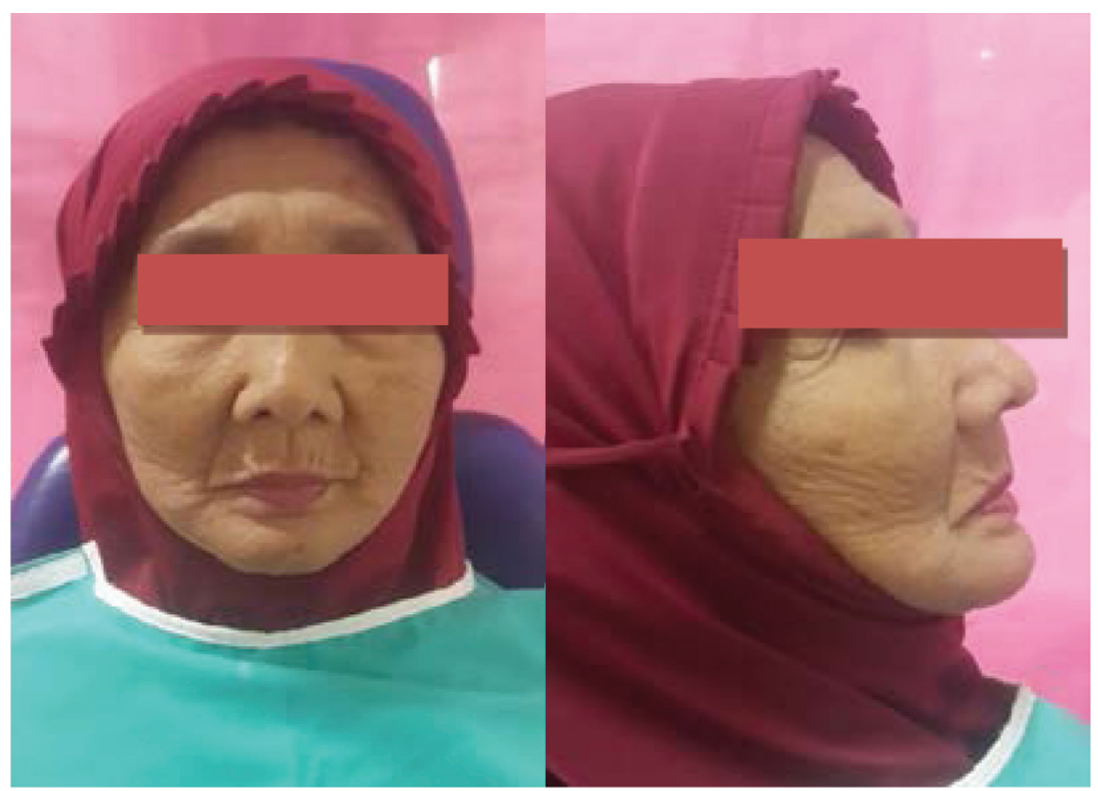

Figure 1 Front and side appearance of patient

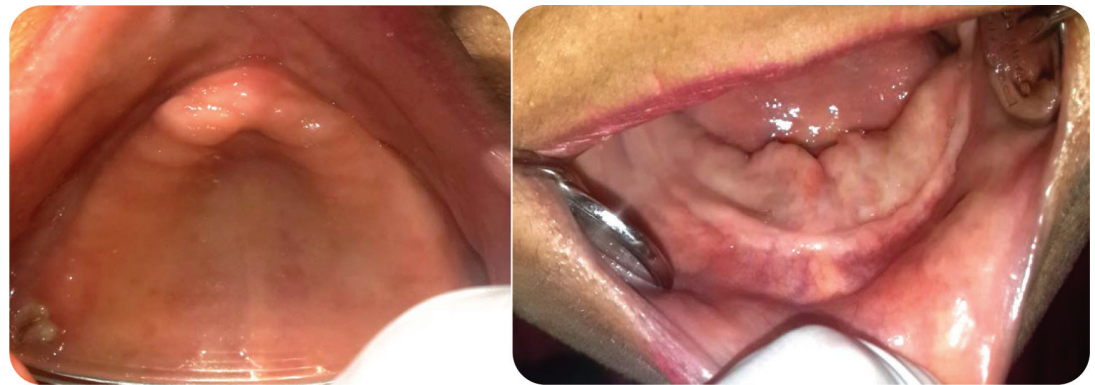

Figure 2 Appearance of patient intra oral

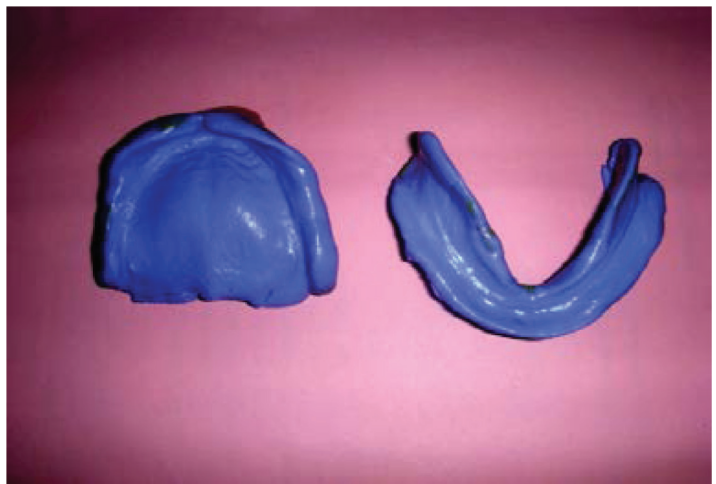

Figure 3 Physiological shaping

nation of bite rim of upper jaw, vertical dimension determination, note making of upper jaw relation and lower jaw in the center relation position and then putting bite rim of upper jaw and lower jaw in articulation were carried out.

The conducted anterior teeth formation and tried in to the anterior teeth of the patient. Next step was conducting posterior teeth formation with lingualized occlusion. Lingualized occlusion is made by putting cusp of posterior teeth palatal of upper jaw in fosa centralis of posterior teeth of lower jaw figure 4.



Figure 4 Teeth formation
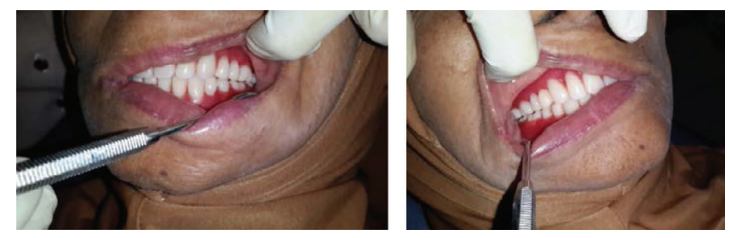

Figure 5 Try in Denture in patient's mouth

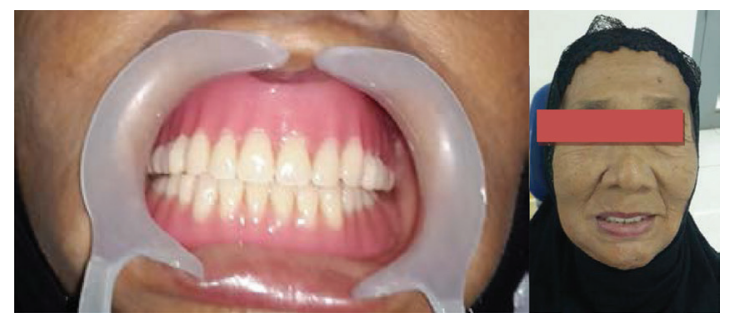

Figure 6 Insertion of denture
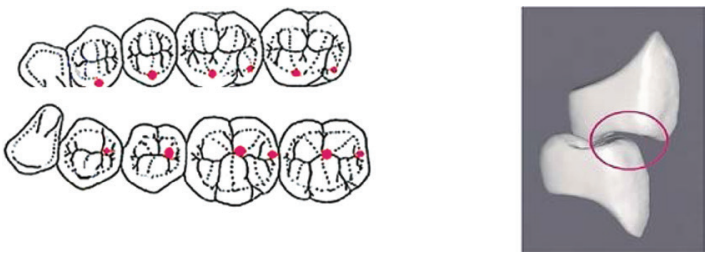

Figure 7 Occlusion point in lingualized occlusion

After teeth formation in articulation then non original tooth tried on to the patient figure 5 and if it is fit then creamed to be packed.

After lab process, denture was inserted to the patient figure 6. Patient was also instructed about the way to put and to take out the denture, the way to clean the tooth and control $1 \times 24$ hours, then 2 weeks, 1 month and finally after 3 months.

\section{Discussion}

Jaw relation is defined as the relation between upper and lower jaw. In this case the relation between patients jaw was abnormal relationship. It was because the upper jaw experienced bigger reabsorption of tooth loss and irreplaceable with denture compared to the lower jaw. This appeared to become jaw relation of pseudo class III. Then to gain 
natural look and stability, posterior teeth formation with lingualized occlusion was conducted. ${ }^{6,7}$

Teeth formation in lingualized occlusion is that cups palatal of upper jaw posterior in fosa centralis of lower jaw. The concept of lingualized occlusion is applying anatomic denture in artificial teeth with non anatomic denture in the lower jaw. This concept was introduced by Alfred Gyte, SH Payne called cusp to-fossa occlusion or lingualized occlusion. ${ }^{6,7}$

In some in vivo and in vitro studies said that lingualized occlusion in patient figure 7 with full denture has stabile, retention, aesthetic and comfort optimum chew experience. It is also stated that lingualized occlusion can be very effective in the application of full denture opposite with partial denture. By only cusp palatal of the upper jaw contacted with fosa centralis of lower jaw, there is only one or two contact conducts. Cusp palatal contacted when centric, balance, working, furthermore for this reason, all pressures appear during working movement and balancing reduce naturally created stability. ${ }^{6-8}$

\section{Conclusion}

The relationship of pseudo class III occurred in some patients with partial tooth loss because of resorption process in none tooth area faster than that in the tooth are. It occurs because the upper jaw which loss most of the teeth have resorption of normal bone, those move forward, backward or up with progressive response meanwhile it recognized smaller than those in the lower jaw. In conclusion, one of the treatment conducted is to perform teeth foundation in occlusion pattern of lingualized occlusion which gives natural appearance in patient and stability of denture.

\section{References}

1. Jogersen EB. Restoration of the partially edentulous mouth: a comparison of overdentures, removable partial dentures, fixed partial dentures and implant treatment. J Dent 1996;24: 237-244.

2. Winkler S. Clinical implant site development and Alveolar bone resorption. Philadelphia.

3. Prasad DKB, Prasad R, Bardia A, et al. Enhancing stability. A review of various occlusal schemes in complete denture prosthesis. NUJHS 2013;3: 105-112.

4. Ahmed AR, Muneer MU, Hakeem S. Masticatory efficiency between balanced and lingualized occlusion in complete denture wearers. PODJ 2013;33: 200-206.

5. Petruska L. Utilizing lingualized posterior occlusion in the construction of complete denture. J Dent Tech 2011: 11-14.

6. Hornischer TG. The importance of lingualized occlusion. J Dent Tech 2009: 20-24.

7. Kimoto S, Yamakawa A, Ajiro H, et al. Prospective clinical trial comparing lingualized occlusion to bilateral balanced occlusion in complete dentures. A pilot study. J Int Pros 2006;19: 103-109.

8. Becker CM, Swoope CC, Guckes AD. Lingualized occlusion for removable prosthodontics. J Prosthet Dent 1977;38: 601-608.



This work is licensed under a Creative Commons Attribution 